\title{
Role of Neurosonography in evaluation of brain abnormalities in neonates
}

\section{P Vishwanath Reddy}

\author{
Assistant Professor, Department of Radiology, Prathima Institute of Medical Sciences, Naganoor, \\ Karimnagar, Telangana, India
}

DOI:10.47799/pimr.0901.06

Date of Receiving 7-02-2021

Date of Peer review 15-02-2021

Date of Acceptance 20-02-2021

\section{ABSTRACT:}

Background: Brain damage in preterm infants may result from a series of eventsrather than one specific insult. Maturational characteristics with a failingadaptation capacity may predispose the brain to harmful events during bothintrauterine and extrauterine life. The study aimed to detect anomalies in the brain of neonates with neurosonography.

Methods : the studywas conducted on patients with clinically suspected lesions in the brain, undergoing NSG for evaluation of brain abnormalities in Prathima Institute ofmedical sciences, Karimnagar.Neurosonographic examinations were performed through anteriorfontanelle in both the coronal and sagittal planes.The examination started in the coronal plane along the coronal suture, with a transducer angled towards the frontal region. Then brain was examined invarious coronal planes by sweeping the transducer from anterior to posterior.

Results : The most common abnormality found on neurosonogram in $3-5$ days was germinal- matrix haemorrahge comprising $n=13(31 \%)$ followed by PVL $n=12$ (28.6\%), cyst $n=5$ (11.9\%), flaring $n=5(11.9 \%)$, cerebral edema $n=4(9.5 \%)$, congenital lesions $n=2(4.8 \%)$ and infections $n=1$ (2.4\%). Follow up scan was performed around 2 nd week of life, $n=24$ (57.1\%) neonates were showing normal neurosonogram findings, remaining 18 (43\%) showing abnormal findings, which are PVL $n=6(14.3 \%), G M H n=9$ (21.4\%), cyst $n=1(2.4 \%)$, cerebral edema $n=1(2.4 \%)$ and congenital lesions $n=1(2.4 \%)$.

Conclusion: High incidence of brain injuries was detected in babies born less than 32 weeks of gestation, weighing less than $1500 \mathrm{gm}$. The commonest clinical presentation was seizures followed by absent suckling and lethargy. The abnormalities found on the neurosonogram in our study were germinal matrix hemorrhage, periventricular leukomalacia, cystic PVL, corpus callosum agenesis, and TORCH infection.The mortality rate was high in grade III and grade IV GMH.10-14 days followup scan detected new cases of cystic PVL which were not diagnosed in the initial scan.

Keywords: Neurosonography, Brain Anomalies, Preterm Neonates.

\section{INTRODUCTION :}

The new-born brain is vulnerable to injury from many causes, likepreterm delivery, hypoxia, trauma, etc, resulting in significant mortality andmorbidity despite recent improvements in neonatal intensive care.Neurosonography is a tool in the diagnosis of hemorrhageand other acquired and congenital brain pathology of the new-born. Prematureneonates are especially at risk for intracranial problems. Neuroimaging assessment of premature is becoming increasinglyimportant as the number of premature births is increasing and survival rate ofvery low birth weight babies is also increasing, and survivors remain at greatrisk for neurodevelopment impairments. ${ }^{[1]}$ Approximately $10 \%$ of newborn are born prematurely. Of thesechildren, more than $10 \%$ will sustain neurological injuries leading to significantlearning disabilities, motor developmental delay, cerebral palsy, seizures, andmental retardation. ${ }^{[2]}$ Several types of brain injuries may occur secondary to hemodynamicalterations in premature infants including white matter injury, germinal matrixhemorrhage, intraventricular hemorrhage, periventricular leucomalacia, andcerebellar hemorrhage and atrophy.The hemodynamic instability associated with preterm birth is related tothese brain injuries as $40 \%$ have their onset within 5 hours of birth and $90 \%$ within the first 4 days. They are unusual after 34 weeks of gestation. ${ }^{[3]}$ Neonatal sonography of the brain is now an essential part of new-borncare, particularly in high-risk and unstable premature infants. Currentultrasound technology allows for rapid evaluation of infants in intensive carenurseries with virtually no risk. ${ }^{[4]} \mathrm{CT}$ is not typically used in the premature infant because of 
theinstability of the infant and the lack of good grey / white matter differentiationfrom the high-water content in the newborn brain.The advantages of sonography over computed tomography (CT) /magnetic resonance imaging (MRI) include portability, lower cost, speed, noionizing radiation, and no sedation. Screening of premature infants forintracranial hemorrhage has proven highly sensitive and specific. Ultrasoundis essential to the neonatal evaluation and follows up of hydrocephalus andperiventricular leukomalacia (PVL). ${ }^{[4]}$ We in the current study tried to assess the severity of brain injury by grading the neurosonographic findings.

\section{Material and Methods}

A prospective study of $n=42$ preterm neonates with suspected braininjuries was conducted in the department of Radiodiagnosis, Prathima Institute ofmedical sciences, Naganoor, Karimnagar.

Inclusion criteria

1. Neonates with abnormal neurological presentation seizures, lethargy,

2. apnoea, sudden onset pallor, increase in muscle tone, bulging anterior

3. fontanel.

4. All preterm and term neonates.

\section{Exclusion criteria}

1. All cases were suspected to have trauma and failed resuscitation.

\section{Age greater than one month of age}

Based on the inclusion criteria, we enrolled $n=42$ patients admitted inData for the studywere collected from patients with clinically suspected lesions in the brain, undergoing NSG for evaluation of brain abnormalities in Prathima Institute ofmedical sciences, Karimnagar.

\section{Preparation of the patient}

- Neonates were transported to the ultrasound room by wrapping them in warm clothing to maintain normal body temperature.

- The baby was fed adequately before the examination.

- No sedation was used

- The baby was laid supine.

- Hand washing and cleansing of the transducer was done.

Equipment: All the neonates in this study underwent neurosonogram usinga curvilinear transducer and linear assay high-frequency transducer of Philipsultrasound equipment.
Sonography technique: Neurosonographic examinations were performed through anteriorfontanelle in both the coronal and sagittal plane.The examination started in the coronal plane along the coronal suture, withthe transducer angled towards the frontal region. Then brain was examined invarious coronal planes by sweeping the transducer from anterior to posterior.Following the completion of an examination in the coronal plane, sagittal andparasagittal scans were obtained by placing the transducers on the anteriorfontanel, perpendicular to the coronal plane, and then sweep from midline throughthe lateral ventricles, lateral parenchyma on each side.Care was taken to maintain symmetry throughout the examination, asdensely echogenic choroid plexus appear larger on one side causing a falseimage of subependymal hemorrhage. Posterior fossa screening was done byobtaining axial images through posterior and mastoid fontanel. An initialneurosonogram was done within 7 days of birth and a follow-up scan wasdone at 10-14 days of age.

Statistical analysis: Descriptive statistical analysis has been carried out in thepresent study. Results on continuous measurements are presented on Mean \pm SD (Min-Max) and results on categorical measurements are presented innumber (\%).Repeated measures analyses of variance were conducted and analyzed bypaired t-test. The constituents of lesions in each phase were compared bystudent t-test. A p-value less than 0.05 was considered statistically significantat the $95 \%$ confidence interval. Chi-square test has been used to find thesignificance of the association of NSG scan findings with the final diagnosis.Diagnostics statistics such as sensitivity, specificity, PPV, NPV, and accuracyhas been used to find the correlation of NSG with the final diagnosis.

\section{Results}

Our study comprising of $n=42$ neonates with suspected brain injuries showed the following results. The study group had male predominance 29 (69\%) comparatively withfemale neonates $13(31 \%)$. The majority of babies were born to multiparous women $28(66.7 \%)$ comparedwith primigravida 14 (33.3\%).The most common abnormality found on neurosonogram was germinal matrix hemorrhage comprising $n=13(31 \%)$ followed by PVL $n=12(28.6 \%)$, cyst $n=5(11.9 \%)$, flaring $n=5(11.9 \%)$, cerebral edema $n=4(9.5 \%)$, congenital lesions $n=2(4.8 \%)$ and infections $n=1(2.4 \%)$ (Table 1$)$.

Table 1: Lesion wise distribution of cases

\begin{tabular}{|l|c|c|}
\hline $\begin{array}{c}\text { Neurosonography } \\
\text { findings }\end{array}$ & No. of cases & Percentage \\
\hline Flaring & 5 & 11.9 \\
\hline PVL & 12 & 28.6 \\
\hline GMH & 13 & 31.0 \\
\hline
\end{tabular}




\begin{tabular}{|l|c|c|}
\hline Cyst & 5 & 11.9 \\
\hline Cerebral edema & 4 & 9.5 \\
\hline Congenital Anomalies & 2 & 4.8 \\
\hline Infections & 1 & 2.4 \\
\hline Total & 42 & 100 \\
\hline
\end{tabular}

In our study Out of the $\mathrm{n}=42$ neonates studied, $\mathrm{n}=32$ (76.1\%) were preterm and $\mathrm{n}=10(23.9 \%)$ were term. The most common abnormality in preterm found on neurosonogram was germinal- matrix haemorrahge comprising $n=11$ (34.4\%) fallowed by PVL $n=10(31.3 \%)$, cyst $n=4(12.5 \%)$, flaring $n=3$ (9.4\%), cerebral edema $n=3(9.4 \%)$, congenital anomalies $\mathrm{n}=1(3.1 \%)$. The most common abnormality in term found on neurosonogram was germinal- matrix haemorrahge comprising 3 (30\%) fallowed by PVL 2 (20\%), cyst 1 (10\%), cerebral edema $2(20 \%)$, congenital anomalies $1(10 \%)$ and infections $1(10 \%)$ (table 2).

Table 2:Preterm wise distribution of cases

\begin{tabular}{|l|c|c|c|c|}
\hline \multirow{2}{*}{$\begin{array}{c}\text { Neurosonography } \\
\text { findings }\end{array}$} & \multicolumn{2}{|l|}{\begin{tabular}{c} 
Preterm Neonates \\
\cline { 2 - 5 }
\end{tabular}} & \multicolumn{2}{c|}{ Term Neonate } \\
\hline cases & & $\begin{array}{c}\text { No. of } \\
\text { cases }\end{array}$ & $\begin{array}{c}\text { Percen- } \\
\text { tage }\end{array}$ \\
\hline PVL & 3 & 9.4 & 0 & 00 \\
\hline GMH & 10 & 31.3 & 2 & 20 \\
\hline Cyst & 11 & 34.4 & 3 & 30 \\
\hline Cerebral edema & 3 & 9.4 & 2 & 20 \\
\hline Congenital anomalies & 1 & 3.1 & 1 & 10 \\
\hline Infections & 0 & 0.0 & 1 & 10 \\
\hline Total & 32 & 100 & 10 & 100 \\
\hline
\end{tabular}

The study group comprises babies born between the gestational age of 28 to $39 \mathrm{wks}$ of which the majority of them were between 30-34 wks and 34-37wks comprising $n=12$ (28.6\%) and $n=12(28.6 \%)$ respectively. Others were comprising $<30$ wks $n=10(23.8 \%)$ and $>37$ wks $n=8(19 \%)$. Birth weight was ranging from 0.8 to $3.1 \mathrm{~kg}$ of which most babies werebetween $<1.5 \mathrm{~kg} 14$ (33.3\%). Others comprising of 2-2.5 kgs were $12(28.6 \%),>2.5 \mathrm{kgs}$ were $8(19 \%)$ and $1.5-2 \mathrm{kgs}$ were 8 (19\%).

The most common abnormality found on neurosonogram in $3-5$ days was germinal- matrix haemorrahge comprising $n=13$ (31\%) followed by PVL $n=12(28.6 \%)$, cyst $n=5(11.9 \%)$, flaring $n=5(11.9 \%)$, cerebral edema $n=4(9.5 \%)$, congenital lesions $n=2(4.8 \%)$ and infections $n=1$ (2.4\%). Follow up scan was performed around 2 nd week of life, $n=24(57.1 \%)$ neonates were showing normal neurosonogram findings, remaining $18(43 \%)$ showing abnormal findings, which are PVL $n=6(14.3 \%), G M H n=9$ (21.4\%), cyst $n=1(2.4 \%)$, cerebral edema $n=1(2.4 \%)$ and congenital lesions $n=1(2.4 \%)$.

Table 3: Neurosonography findings between 10-14 days

\begin{tabular}{|l|c|c|}
\hline \multicolumn{1}{|c|}{ Findings } & No. of cases & Percentage \\
\hline Normal & 24 & 57.1 \\
\hline Flaring & 0 & 0.0 \\
\hline PVL & 6 & 14.3 \\
\hline GMH & 9 & 21.4 \\
\hline Cyst & 1 & 2.4 \\
\hline Cerebral edema & 1 & 2.4 \\
\hline Congenital anomalies & 1 & 2.4 \\
\hline Infections & 0 & 0.0 \\
\hline Total & 42 & 100 \\
\hline
\end{tabular}

The commonest clinical manifestation of babies with suspected brain injuriesin our study was seizures $n=11(26.11 \%)$ followed by absent suckling $n=8(19 \%)$ and lethargy $n=7$ (16.7\%).

Table 4: Distribution of various clinical presentations

\begin{tabular}{|l|c|c|}
\hline \multicolumn{1}{|c|}{ Clinical presentations } & No. of cases & Percentage \\
\hline Seizures & 11 & 26.2 \\
\hline Lethargy & 7 & 16.7 \\
\hline Absent suckling & 8 & 19.0 \\
\hline Flaccidity & 8 & 19.0 \\
\hline Irritable/excessive cry & 4 & 9.5 \\
\hline Sudden onset pallor & 1 & 2.4 \\
\hline Hypotonia & 2 & 4.8 \\
\hline Hypertonia & 1 & 2.4 \\
\hline Bulging anterior fontanelle & 2 & 4.8 \\
\hline Total & 42 & 100 \\
\hline
\end{tabular}

Perspectives in Medical Research | January-April 2021 | Vol 9 | Issue 1 
Grade I GMH was found in 7 babies (53.8\%) accounting for the majority of GMH, grade II was found in 2 (15.4\%), grade III in 3 (23.1\%), and grade IV in 1 baby (7.7\%). The study group showed mortality in $18(43 \%)$ neonates. Highest mortality was observed in GMH 9 (51\%) followed by PVL 6 (33.3\%), cyst 1 (5.6\%), cerebral edema 1 (5.6\%) and congenital lesions 1 (5.6\%). Grade I GMH was found in 4 babies (22.2\%) accounting for the majority of GMH, grade II was found in 1 (5.6\%), grade III in 3 $(16.7 \%)$, and grade IV in 1 baby (5.6\%).

\section{Discussion}

Neurosonography has now been routinely performed in premature infants. This has produced a wealth of information about the central nervous system like GMH, PVL, and ventriculomegaly. This information has included the timing and evolution of these lesions and their eventual correlation with outcome.The commonest clinical manifestation of babies with suspected braininjuries in our study was seizures $n=11(26.11 \%)$ followed by absentsuckling $n=8(19 \%)$ and lethargy $n=7$ (16.7\%).The most common abnormality found on neurosonogram wasgerminal- matrix hemorrhage comprising $n=13(31 \%)$ followed by PVL $n=12(28.6 \%)$, cyst $n=5(11.9 \%)$, flaring $n=5(11.9 \%)$, cerebral edema $n=4(9.5 \%)$,congenital lesions $n=2(4.8 \%)$ and infections $n=1$ (2.4\%).The study group showed mortality in 18 (43\%) neonates. Highest mortalitywas observed in GMH 9 (51\%) followed by PVL 6 (33.3\%), cyst 1 (5.6\%),cerebral edema 1 (5.6\%) and congenital lesions 1 (5.6\%). The initial sonogramwas performed within 7 days of birth followed by a repeat scan at 10- 14 daysof life. An initial neurosonogram study performed within 7 days of birth showedabnormal findings in $\mathbf{4 2}$ neonates. Follow up scan was performed around the 2ndweek of life, 24 ( 57.1\% ) neonates were showing normal neurosonogramfindings, the remaining 18 (43\%) showing abnormal findings, which are PVL 6(14.3\%), GMH 9 (21.4\%), cyst $1(2.4 \%)$, cerebral edema $1(2.4 \%)$ andcongenital lesions 1 (2.4\%).The term flaring is used to describe the slightly echogenicperiventricular zones, that are seen in many premature infants in the firstweek of life. During this first week, it is not sure if this is a normal variant or asign of PVL grade. Flaring persisting beyond the first week of life is PVL grade 1. Follow up is needed to differentiate flaring from PVLgrade I. The case on the left shows a premature infant with flaring. At followup no cyst formation was found and after the first week, a normalperiventricular white matter was seen.In our total study, 5 (11.9\%) neonates were having flaring, 3 (9.3\%)neonates were preterm and 2 (20\%) were term, weighing between 1600 to 2500 grams. NNagaraj et al; ${ }^{[5]}$ In their prospective study conducted over 62 preterm babies with suspected neurological injuries were included, concluded abnormalities in preterm neonates is $16.1 \%$. There were $62.9 \%$ male and $37.1 \%$ female neonates. $11.2 \%$ of these had evidence of intracranial bleed, $1.6 \%$ periventricular echogenicity, $1.6 \%$ had ventriculomegaly and $1.6 \%$ had periventricular leukomalacia. The most common abnormality was grade I GMH (about 27.4\%).Prithviraj D et al;[6]found the incidence of neurosonographic abnormalities in high-risk neonates is $31 \%$ in the study. Of this $41 \%$, had evidence of intracranial bleed, $25 \%$ had cerebral edema, 6\% periventricular leukomalacia, $16 \%$ hyperechogenic thalami, and one had ventriculomegaly. VP Chinta et al; ${ }^{[7]} \mathrm{N}=48$ found Germinal matrix hemorrhage (GMH) was the commonest abnormality (67.02\%). In 199 asymptomatic premature babies, cranial sonography was abnormal in 51 (25.62\%) cases. A Priyadarshi et al; [8] revealed abnormalities in cranial ultrasound in $26.7 \%$ of preterm neonates. $12.5 \%$ of those had evidence of intracranial hemorrhage, $7.1 \%$ with transient periventricular echogenicity (TPVE), 1.7\% had ventriculomegaly, 3.5\% had periventricular leukomalacia and $1.7 \%$ had a cystic lesion.J G Flores et al; ${ }^{[8]}$ in a retrospective study of $n=28$ patients who underwent a fetal MRI study for suspected congenital neurological anomalies. The diagnoses obtained by neurosonography and MRI were collected and compared. The fetal MRI examination revealed fetal ventriculomegaly, posterior fossa anomalies, suspected midline defects, small-for-gestational-age cephalic biometry, and confirmed congenital CMVinfection.

\section{Conclusion}

A high incidence of brain injuries was detected in babies born less than 32 weeks of gestation, weighing less than 1500 gm. The commonest clinical presentation was seizures followed by absent suckling and lethargy. The abnormalities found on the neurosonogram in our study were germinal matrix hemorrhage, periventricular leukomalacia, cystic PVL, corpus callosum agenesis, and TORCH infection.The mortality rate was high in grade III and grade IV GMH.10-14 days follow-up scan detected new cases of cystic PVL whichwere not diagnosed in the initial scan.

\section{REFERENCES}

1. Martin JA, Hamilton BE, Ventura SJ, Menacker F, Park MM. Birthsfinal data for 2000. Natl Vital Stat Rep. 2002;50:1101.

2. Back SA, Rivkees SA. Emerging concepts in periventricular whitematter injury. Semin Perinatol. 2004;28(6):405-14.

3. Volpe JJ. Neurological evaluation; hypoxic-ischemic encephalopathyand intracranial hemorrhage. In: Neurology of the newborn. Thirdedition. Philadelphia, Pennsylvania, W.B. Saunders Company1995; 95-463.

4. Rumack CM, Drose JA. Neonatal and infant brain imaging. In:Diagnostic ultrasound. 4th edn. Philadelphia, Elsevier, Mosby.2011;1558-163. 
5. Niranjan Nagaraj, Sarika Swami, Pramod Kumar Berwal, Anusha Srinivas, Gautam Swami. Role of Cranial Ultrasonography in Evaluation of Brain Injuries in Preterm Neonates. Indian Journal of Neonatal Medicine and Research. 2016; 4(2):5-8.

6. Prithviraj D, Reddy B, Reddy R, Shruthi B. Neurosonogram in Critically ill Neonates in Neonatal Intensive Care Unit. Int J Sci Stud2016;4(1):124-128.

7. Vittal Prasad China. Evaluation of cranial sonography indices in infants and neonates. Int J Med Sci Public Health. 2016; 5(7): 1492-1495.

8. JG Flores, Manuel Rico Uriel, Carrascoso, Mercedes Espada, Ricardo Sáinz de la Cuesta. Fetal magnetic resonance imaging and neurosonography incongenital neurological anomalies: supplementary diagnostic and postnatal prognostic value. The journal of maternal-fetal and neonatal medicine.2013;23(15):1517-1523.

How to cite this article : P Vishwanath Reddy. Role of Neurosonography in evaluation of brain abnormalities in neonates. Perspectives in Medical Research 2021; 9 (1):26-30 DOI:10.47799/pimr.0901.06

Sources of Support: Nil, Conflict of interest: None declared 